\title{
INTERVENÇÃO BREVE EM ORGANIZAÇÕES: MUDANÇA EM COACHING DE EXECUTIVOS ${ }^{1}$
}

\author{
Sueli Aparecida Milaré \\ Elisa Medici Pizão Yoshida\#
}

\begin{abstract}
RESUMO. Coaching de executivos é um processo de suporte a profissionais visando ao atingimento de metas organizacionais por meio da aprendizagem de novas competências. Diferentes propostas foram apresentadas na literatura, sem ou com poucas evidências empíricas de eficiência. O objetivo foi avaliar a eficiência de um programa de coaching desenvolvido e conduzido pela primeira autora, composto por quatro módulos: autopercepção; identificação de melhorias; elaboração/execução do plano de ação e acompanhamento. A amostra se constituiu de dez executivos encaminhados por suas empresas para o programa. A eficiência dos processos foi avaliada comparandose medidas psicológicas finais com iniciais. Foram utilizados os instrumentos Escala Diagnóstica Adaptativa Operacionalizada (EDAO-R), Escala de Estágios de Mudanças (EEM), Personal Profile Analysis (PPA) e Autoanálise do Desempenho (AAD). Os resultados sugerem que o programa de coaching ajudou na melhora da eficácia adaptativa, permitindo o desenvolvimento de competências. O estágio de mudança inicial permitiu escolher a melhor estratégia cognitiva. Limites metodológicos são apontados.
\end{abstract}

Palavras-chave: Mudança comportamental em organizações; instrumentos psicológicos; psicoterapia de executivos.

\section{BRIEF INTERVENTION IN ORGANIZATIONS: CHANGE IN EXECUTIVE COACHING}

\begin{abstract}
Executive coaching is a process designed to help professionals to reach organizational goals by learning new competences. Different proposals have been suggested in the literature with none or few empirical evidences of efficiency. This study aimed to evaluate the efficiency of an executive coaching program developed and carried out by first author, and composed by four modules: self-perception; improvements identification; action plan elaboration / execution and follow-up. Participants were ten executives directed by their companies to accomplish a coaching process. Processes were assessed by comparing final to initial psychological measures. Instruments: Escala Diagnóstica Adaptativa Operacionalizada (EDAO-R), Escala de Estágios de Mudanças (EEM), Personal Profile Analysis (PPA) e Autoanálise do Desempenho (AAD). Results suggested that the coaching improved the level of adaptive efficacy by the development of specific habilities. The initial stage of change allowed choosing the best cognitive strategy. Limits on the methodological were pointed out.
\end{abstract}

Key words: Organizational behavior change; psychological instruments; executive psychotherapy.

\section{INTERVENCIÓN BREVE EN ORGANIZACIONES: MUDANZA EN COACHING DE EJECUTIVOS}

\footnotetext{
RESUMEN. Coaching de ejecutivos es un proceso de soporte a profesionales visando el logro de metas organizacionales a través del aprendizaje de nuevas competencias. Diferentes propuestas fueron presentadas en la literatura, sin o con pocas evidencias empíricas de eficiencia. El objetivo fue evaluar la eficiencia de un programa de coaching desarrollado y conducido por la primera autora, compuesto por cuatro módulos: auto-percepción; identificación de mejorías; elaboración / ejecución del plan de acción y acompañamiento. Muestra compuesta por diez ejecutivos encaminados por sus empresas para el programa. La eficiencia de los procesos fue evaluada comparando medidas psicológicas finales con iniciales. Instrumentos: Escala Diagnóstica Adaptativa Operacionalizada (EDAO-R), Escala de Niveles de Mudanzas (EEM), Personal Profile Analysis (PPA) y Auto Análisis del Desempeño (AAD). Los resultados sugieren que el programa de

1 Apoio: Programa de Capacitação de Docentes da Puc-Campinas.

* Doutora em Psicologia, Docente do Programa de Pós Graduação Stricto Sensu em Psicologia, Pontifícia Universidade Católica de Campinas.

\# Doutora em Psicologia, Docente da Faculdade de Psicologia, Pontifícia Universidade Católica de Campinas.
} 
coaching ayudó en la mejora de la eficacia adaptativa, permitiendo el desarrollo de competencias. El nivel de mudanza inicial ayudó en la elección de estrategias cognitivas. Límites metodológicos son apuntados.

Palabras clave: Mudanza de comportamiento en organizaciones; instrumentos psicológicos; psicoterapia de ejecutivos.

A evolução no mundo do trabalho traz hoje novos desafios que substituem os velhos paradigmas, afetando as relações entre as pessoas. Um dos principais fatores de evolução é o causado pela tecnologia da informação, que tem se desenvolvido a largos passos, e com isto as pessoas precisam estabelecer uma nova relação com o trabalho e o próprio entendimento da realidade vivenciada. Torna-se então necessário o desenvolvimento contínuo dos profissionais diante das mudanças exigidas. A aprendizagem passa a ser determinante para os resultados positivos e necessariamente estimulada por uma liderança que valorize as pessoas (Milaré \& Yoshida, 2007).

Assim estas mudanças estão afetando diretamente as estratégias organizacionais, uma de cujas decisões é optar por um modelo de desenvolvimento de pessoas que privilegie a aprendizagem. $\mathrm{O}$ coaching oferece a oportunidade de ajudar as pessoas a enfrentarem desafios em todos os níveis. Permite-lhes também aprender enquanto estão trabalhando. Etimologicamente, coaching vem de coach, uma palavra antiga com origem em uma pequena vila húngara onde foi desenvolvida a carruagem coberta, chamada koczi. Hendrickson (1987, citado por Stern, 2004) refere sua idealização para proteger seus habitantes das intempéries regionais ao serem transportados de um lugar para outro. Mais recentemente esta palavra tem sido associada ao esporte, ou seja, ao técnico que treina a equipe para que juntos atinjam suas metas em diferentes competições. Conforme com estas definições, o dicionário Oxford (2005) traz a informação de que a palavra coach é sinônima de técnico, treinador, tutor, assim como carruagem, ônibus e viagem em carro ou em carruagem.

Whitmore (2006) afirma que a essência do coaching é liberar o potencial de uma pessoa para maximizar seu desempenho e ajudá-la a aprender em vez de ensiná-la. A evolução do conceito levou à utilização do coaching como forma de desenvolvimento dos executivos. Em termos de definição, pode-se entender o coaching de executivos como

Relação de ajuda entre um cliente que tem autoridade administrativa e responsabilidade em uma organização e um profissional que usa grande variedade de técnicas e métodos comportamentais para ajudar o cliente a atingir o conjunto mutuamente identificado de metas para melhorar seu desempenho profissional e pessoal e, consequentemente, melhorar a efetividade da organização do cliente dentro de um acordo de coaching formalmente definido (Kilburg, 2000, p. 67).

Muitos motivos justificam o interesse pela utilização desta metodologia, mas o principal é que ela contribui diretamente para a aquisição e amadurecimento de competências, adaptação aos processos de transformação organizacional com melhoria de desempenho (Milaré, 2004). Em relação à origem, Kampa-Kokesch e Anderson (2001) referemse ao termo coaching de executivos como originário do mundo dos negócios, no final da década de 1980. Judge e Cowell (1997) argumentam que a realização de coaching de executivos por consultorias começou ao redor de 1990, embora em ambos os artigos se mencione haver evidências de que ele teria surgido anteriormente. Harris (1999) menciona três fases na história do desenvolvimento do coaching de executivos. A primeira se situaria entre os anos de 1950 e 1979, quando alguns profissionais usaram uma mistura de desenvolvimento organizacional e técnicas psicológicas em trabalho com executivos; a segunda compreenderia o período de 1980 a 1994, quando ocorreu um aumento do profissionalismo e o início de serviços padronizados (entretanto uma padronização completa ainda não aconteceu e talvez nem seja desejável, já que cada caso é um caso e a dinâmica das instituições varie muito); e a terceira fase iria de 1995 até o presente, quando há um aumento de publicações e o estabelecimento de uma organização profissional para coaching, a Professional and Personal Coaches Association, mais recentemente denominada International Coaching Federation (ICF), associação profissional mundial, sem fins lucrativos, de coaches pessoal e de negócios (personal and business coaches), que tem contribuído para a estruturação do campo mediante a organização de congressos e encontros internacionais e publicações específicas da área.

Entre os temas emergentes sobre o assunto encontram-se publicações sobre a melhor abordagem teórica para o sucesso do coaching. Os fundamentos da abordagem cognitivo-comportamental têm se mostrado úteis na condução de processos de coaching de executivos (Milaré, 2004). Algumas pessoas têm rapidamente aprendido a identificar e classificar seu pensamento, para mudá-lo em seu próprio benefício, especialmente se mostrarem motivação para isso. 
Muitas pessoas podem aprender esta técnica com relativa facilidade e podem implementar mudanças significativas e mantidas quando alguém, um técnico ( $\underline{\text { coach }})$, consistentemente relembra e reforça estas mudanças por um período de tempo. É adaptável ao ambiente corporativo de negócios. É fácil de explicar e os executivos podem rapidamente ver o foco de trabalho e o seu benefício potencial. Mesmo assim, as pessoas têm a tendência de retornar aos seus antigos padrões de comportamento e esta abordagem permite reforçar, periodicamente, os novos comportamentos aprendidos, podendo até pedir a colaboração de pares ou subordinados, caso não traga prejuízos ao cliente (Peltier, 2001). Além disso, existe uma variedade de técnicas cognitivo-comportamentais especificamente criadas para o gerenciamento de estresse que estão disponíveis para as pesssoas atendidas em programas de coaching (Judge \& Cowell, 1997; Lipp, 2005). Qualquer modelo de coaching de executivos deve levar em conta que o participante deste processo é alguém com alto desempenho em sua organização e que a intervenção precisa levar a efeitos significativos e duradouros de desenvolvimento. A expectativa é que o executivo submetido ao coaching cognitivocomportamental para desenvolver suas próprias habilidades esteja em condições de aplicar os princípios cognitivo-comportamentais para seus subordinados diretos, com o que possivelmente fará aumentar o desempenho de outros membros de suas unidades de trabalho (Ducharme, 2004; Peltier, 2001). Neste sentido, o feedback fornecido pelo coach ao executivo trará impacto nos outros dentro e fora da organização. Ao receber este tipo de feedback os executivos aumentam sua autoconsciência e autoestima, evidenciando um importante princípio subjacente ao coaching: o aumento da consciência psicológica e social dos executivos, o que por sua vez poderá aumentar a moral, produtividade e lucros (Kilburg 2000; O'Neill, 2001).

Também como suporte ao programa de coaching de executivos pode-se citar a utilidade da Teoria DISC (acrônimo de Dominância, Influência, Estabilidade e Conformidade) e o emprego do instrumento PPA (Personal Profile Analysis). Neste enfoque, Marston (1928), ao tentar compreender e sistematizar modelos de interação entre os indivíduos e seus ambientes, elaborou duas proposições básicas: uma biossocial, que destaca a interdependência das emoções, ações e ambientes; e uma que se refere aos diferentes mecanismos utilizados pelas pessoas na busca pelo prazer e harmonia e consequente afastamento da dor, hostilidade e desprazer. Os fatores comportamentais representam, nesse contexto, modalidades básicas de reação comportamental a partir da percepção (mais hostil ou amigável) que o sujeito tenha de seu ambiente. Definiu então que dois tipos de percepção são importantes para explicar as respostas das pessoas em situações particulares: a percepção do ambiente e a percepção de si mesmas. Utilizando-se destes conceitos, o psicólogo americano Thomas Hendrickson (1950, citado por Thomas International, 1996) adaptou-os para o contexto do trabalho e da administração. Sistematizou essa abordagem num procedimento intitulado Análise do Perfil Pessoal PPA. O estilo comportamental de cada indivíduo é a combinação dos altos e baixos dos quatro fatores comportamentais identificados pela teoria DISC. Considera-se relevante para o programa de coaching de executivos a realização do PPA. Para o exercício da atividade de liderança, o que se espera do executivo é que ele tenha bem evidenciado em seu perfil a alta influência e a alta dominância (Duarte 2006). Estudos brasileiros trazem a mesma solicitação de perfil para executivos: a predominância do perfil influência e, em segundo plano, a dominância, como necessários ao desempenho de líderes empreendedores (Target Training International, 2000). Estas características estariam relacionadas à eficácia adaptativa demonstrada.

De acordo com Yoshida (1999), a avaliação da configuração adaptativa de candidatos a psicoterapias, por meio da Escala Diagnóstica Adaptativa Operacionalizada - EDAO-R (Simon, 1995), fornece base segura dos recursos da pessoa em termos de capacidade de enfrentamento e de flexibilidade de respostas diante de seus problemas, constituindo-se em critério prognóstico da qualidade dos resultados terapêuticos de sujeitos que concluem atendimentos, ou seja, os pacientes que apresentam melhor eficácia no início do processo terapêutico são também os que apresentam melhores resultados, com mudanças mais significativas na qualidade da adaptação, enquanto aqueles que possuem configurações adaptativas ineficazes, severas ou graves tendem a abandoná-lo antes do término.

Além da avaliação da eficácia adaptativa, Yoshida e Enéas (2004) sugerem que se considere a necessidade de mudança manifesta pelo paciente. Dito de outra forma, o critério adaptativo é necessário mas não é suficiente como prognóstico de mudança. É preciso que o paciente reconheça que tem um problema e que esteja disposto a enfrentá-lo. O reconhecimento de que se tem um problema e a disposição para enfrentá-lo podem ser identificados por meio do conceito de estágios de mudança proposto por DiClemente e Prochaska (1982). Cada estágio 
reflete o nível de consciência de um problema e o grau despendido de esforço para enfrentá-lo. Foram identificados cinco diferentes estágios de mudança: de pré-contemplação, contemplação, preparação, ação e término. Uma escala desenvolvida para avaliação destes estágios foi proposta por McConnaughy, Prochaska e Velicer (1983) - EEM - Escala de Estágios de Mudança.

Em psicoterapia pressupõe-se que o paciente esteja no estágio de contemplação para encontrar-se disposto a enfrentar seus conflitos, e quanto melhor a qualidade de suas respostas adaptativas, maiores serão as chances de o processo psicoterápico ser bemsucedido (Yoshida \& Enéas, 2004). De forma semelhante, no coaching de executivos tem sido observado que as atitudes positivas e abertura em relação ao desenvolvimento do programa fazem com que o processo seja mais fluido, passando pelos módulos de forma consistente e com evolução gradual. Também tem sido observado que as mudanças obtidas por alguns, principalmente por aqueles com maiores dificuldades no setor afetivo-relacional, não possuem a mesma rapidez e consistência observadas em outros (Milaré \& Yoshida, 2007).

Com base em analogias feitas entre os processos psicoterapêuticos e os de coaching de executivos, hipotetizou-se que o estágio de mudança do início do processo e o grau de eficácia adaptativa do executivo estariam associados à possibilidade de mudança num programa de coaching. Para verificação desta hipótese foi realizado o acompanhamento de programas de coaching de executivos realizados dentro dos procedimentos propostos pela primeira autora, composto de três etapas: formalização do contrato da empresa cliente - que se inicia com reuniões de levantamento de necessidades e expectativas do cliente e necessidades de desenvolvimento de novas competências junto à empresa cliente (pessoa jurídica que procura o programa para um de seus executivos), junto ao superior imediato do participante; 2. formalização do contrato com o participante: inicia-se com a formalização da proposta ao profissional alvo do coaching (participante), quando são informados os resultados esperados, cronograma e local das reuniões, assim como as regras do contrato como ausências, atrasos, desistências, etc.; e 3) a etapa de avaliação dos resultados, que é realizada em reunião do profissional responsável pelo coaching e o representante da empresa cliente. O conteúdo desta reunião já foi discutido anteriormente com o participante, que já deve ter dado permissão para exposição de seus dados. Nela, os resultados alcançados são comparados com os esperados e previstos no início do programa.
Ao longo das três etapas, quatro módulos compõem a essência do programa de coaching de executivos propriamente dito (Milaré, 2003): 1) a autopercepção (atingida por meio de entrevistas, avaliação do PPA realizada pelo profissonal e autoanálise do desempenho pelo participante, por meio do preenchimento da AAD, de autorrelato); 2) identificação das oportunidades de melhoria; 3) elaboração e execução do plano de ação e 4) acompanhamento. Os formulários, instrumentos e questões são partes integrantes do Manual do Programa de Coaching (Milaré, 2003), que fica em poder do participante. Em todas as etapas este é levado a refletir sobre as mudanças requeridas pela empresa cliente. Poderá haver divergência entre o posicionamento de um e o de outro. Diante deste tipo de situação, o profissional fará a intermediação necessária entre ambos, para se chegar a um consenso. $\mathrm{O}$ foco dirigido ao resultado deve ajustar-se bem à necessidade do executivo, atendendo a assuntos específicos. A aquisição de habilidades para facilitar o crescimento na organização e a eliminação de comportamentos mal-adaptativos formam a base das técnicas cognitivo-comportamentais utilizadas. $\mathrm{O}$ programa é acompanhado pelo profissional e imediatamente antes do enceramento é avaliado pelo participante.Nesta ocasião são resgatadas as oportunidades de melhoria em relação à situação atual do participante.

Utilizado na prática profissional da primeira autora, o programa não contava até então com evidência científica sobre sua eficiência. Neste sentido, o objetivo do estudo foi avaliar os resultados do programa de coaching de executivos para profissionais em cargos de comando em organizações. Executivos submetidos ao programa foram avaliados nas etapas inicial e final de seus respectivos programas de coaching quanto à eficácia adaptativa e ao estágio de mudança em que se encontravam. Além disto, foram avaliadas qualitativamente, em cada processo, possíveis relações entre a eficácia adaptativa, o estágio de mudança e os dados obtidos por meio dos instrumentos de avaliação utilizados no programa e da integração dos dados revelados nos processo individuais, traçando um quadro geral das mudanças.

\section{MÉTODO}

\section{Participantes}

A amostra constituiu-se de dez profissionais que realizaram programas de coaching de executivos com

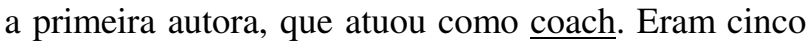


mulheres e cinco homens, cujas idades variaram entre 36 e 52 anos (média de 43 anos e mediana de 41 anos), a saber: seis executivos com nível de comando em organizações multinacionais de grande porte e privadas, dois de empresas nacionais privadas de grande porte e dois de empresas nacionais públicas de pequeno porte. Nove foram indicados para programa de coaching pelas respectivas empresas e um o buscou por iniciativa própria. Seis executivos eram pósgraduados (especialistas) e os demais graduados em nível superior. Todos forneceram o consentimento livre e esclarecido para sua participação. O projeto de pesquisa foi aprovado pelo Comitê de Ética para Pesquisas com Seres Humanos da PUC - Campinas (Protocolo 392/06).

\section{Medidas de avaliação}

Como medidas de avaliação foram utilizadas a Escala Diagnóstica Adaptativa OperacionalizadaRedefinida (EDA)-R), a Escala de Estágios de Mudanças (EEM), a Personal Profile Analysis (PPA) e a Autoanálise de Desempenho (AAD),

A Escala Diagnóstica Adaptativa Operacionalizada-Redefinida/ EDAO-R, desenvolvida por Simon (1989), foi utilizada para avaliação da eficácia adaptativa A classificação da qualidade da adaptação é feita por setores da personalidade (afetivo-relacional e de produtividade). Atribui-se um escore a cada setor, em função do grau em que as respostas dadas pelo sujeito resolvam o problema, tragam satisfação e evitem conflito interno ou externo. Da somatória dos escores resultam cinco grupos possíveis (Simon, 1997): Grupo I, Adaptação eficaz; Grupo II, Adaptação ineficaz leve; Grupo III, Adaptação ineficaz moderada; Grupo IV, Adaptação ineficaz severa; Grupo V, Adaptação ineficaz grave.

A Escala de Estágios de Mudanças/EEM, desenvolvida por McConnaughy, Prochaska e Velicer (1983), de autorrelato, tem a finalidade de avaliar os estágios de mudança segundo o nível de consciência manifesto pelo sujeito em relação ao seu problema e ao esforço despendido para enfrentar este problema. A escala é composta por 32 itens, subdivididos em quatro grupos de oito, destinados a avaliar cada um dos seguintes estágios de mudança: pré-contemplação; contemplação; ação e manutenção. As respostas são do tipo Likert de cinco pontos, em que 1 corresponde a "discordo totalmente" e 5 a "concordo totalmente". Pesquisa brasileira de validade de construto reproduziu a estrutura fatorial da escala (Yoshida, Primi \& Pace, 2003).

A Personal Profile Analysis - PPA é um instrumento desenvolvido a partir do modelo conceitual de Marston (1928), que tinha como objetivo compreender e sistematizar modelos de interação entre os indivíduos e seus ambientes. A partir das palavras escolhidas (+ e -) pelo sujeito no formulário do PPA obtém-se uma descrição acurada das características que mais se destacam em seu estilo comportamental. As quatro características analisadas são: dominância; influência; estabilidade e conformidade.

A Auto Análise do Desempenho - AAD é um instrumento desenvolvido a partir do modelo conceitual de Fournies (1978, citado por Darraugh, 2000), que visa a compreensão e sistematização do que estaria influenciando a insatisfação quanto ao desempenho do participante. A proposta é buscar junto ao seu superior imediato uma análise de seu desempenho, principalmente dos esforços realizados para atingir suas metas organizacionais. Com base nestes conceitos, Milaré (2003) desenvolveu um instrumento de auto-relato que busca identificar através das respostas do participante como está seu desempenho e o quanto de feedback tem recebido de seu superior. O questionário é composto de nove perguntas com respostas classificadas como $\underline{\operatorname{sim}}$ ou não.

\section{Procedimento}

1. Os participantes foram atendidos pela primeira autora em sua prática profissional privada, e os processos incluíram as etapas de contrato formal com a empresa, contrato formal com o participante e avaliação dos resultados. Dentro deste processo destacam-se os módulos anteriormente descritos de forma mais detalhada, os quais compõem a essência do programa de coaching de executivo desenvolvido por Milaré (2003), a saber: autopercepção, identificação das oportunidades de melhoria, elaboração e execução do plano de ação e acompanhamento.

2. A autopercepção visa à avaliação do autoconhecimento do participante e ao reconhecimento das oportunidades de melhoria e da necessidade de mudança. Inclui: entrevistas, levantamento da tendência comportamental (por meio da Personal Profile Analysis) - PPA e autoanálise do desempenho - AAD;

3. A identificação das oportunidades de melhoria tem a finalidade de identificar claramente as dificuldades encontradas no exercício do cargo que estão impedindo o participante de atingir suas metas empresariais 
4. A elaboração e execução do plano de ação tem por objetivo o levantamento das ações estratégicas e táticas que o participante poderá adotar para melhorar seu desempenho e atingir as suas metas profissionais.

5. O acompanhamento visa ao exercício das ações identificadas no módulo anterior com o

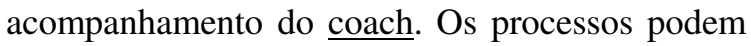
variar quanto ao período de tempo necessário para a sua realização. No caso específico dos processos da amostra, oscilaram entre um máximo de 20 encontros e um mínimo de 6 encontros (duração média de 10 encontros).

$\mathrm{Na}$ análise dos dados foram utilizados a Personal Profile Analysis - PPA e a Autoanálise do Desempenho - AAD, que avaliam aspectos do participante relacionados respectivamente à EDAO $\mathrm{R}$ e à EEM. Avaliações por meio da EDAO-R e da
EEM foram realizadas no início e no final dos programas de coaching de executivos. Com vistas à estimativa do grau de acordo entre avaliadores da EDAO-R, a eficácia adaptativa foi avaliada pelas duas autoras, de forma independente. Para tanto, a segunda autora baseou-se nas transcrições da primeira e da última reuniões com o participante. A integração geral foi realizada por meio do cruzamento dos dados obtidos na EDAO-R e na EEM para cada um dos perfis predominantes da Personal Profile Analysis PPA. A análise dos resultados do istrumento de autorelato AAD ajudou a completar as análises.

\section{RESULTADOS}

As avaliações iniciais e finais da cada participante, segundo cada um dos instrumentos de medida são apresentados na Tabela 1 .

Tabela 1. Avaliação de Cada Participante de Acordo com a Personal Profile Analysis (PPA), Autoanálise do Desempenho (AAD) e Avaliação Inicial e Final da Escala Diagnóstica Adaptativa Operacionalizada Redefinida (EDAO-R) e a Escala de Estágios de Mudança(EEM).

\begin{tabular}{|c|c|c|c|c|c|c|c|}
\hline \multirow[t]{2}{*}{ Coachee } & \multirow[t]{2}{*}{ PPA } & \multirow[t]{2}{*}{ AAD } & \multicolumn{2}{|c|}{ EEM } & \multicolumn{3}{|c|}{ EDAO-R } \\
\hline & & & Inicial & Final & Inicial & Fins & nal \\
\hline A. & Alta Estabilidade e Alta Conformidade & $\begin{array}{l}\text { Desempenho Insatisfatório/ Falta Feedback } \\
\text { Equipe e chefe obstáculos }\end{array}$ & Preparação & Ação & $\begin{array}{c}\text { Grupo } \\
\text { AR } \\
\text { Pr }\end{array}$ & $\begin{array}{c}\text { III } \\
2 \\
1\end{array}$ & $\begin{array}{l}\text { I } \\
3 \\
2\end{array}$ \\
\hline B. & Alta Conformidade e Alta Estabilidade & $\begin{array}{l}\text { Desempenho Insatisfatório } \\
\text { Falta Reconhecimento e Feedback }\end{array}$ & Contemplação & Ação & $\begin{array}{c}\text { Grupo } \\
\text { AR } \\
\text { Pr }\end{array}$ & $\begin{array}{l}\text { II } \\
2 \\
2\end{array}$ & $\begin{array}{l}\text { I } \\
3 \\
2\end{array}$ \\
\hline C. & Alta Influência e Alta Dominância & $\begin{array}{l}\text { Falta Reconhecimento } \\
\text { Não ser aceito pelo chefe }\end{array}$ & Ação & Ação & $\begin{array}{c}\text { Grupo } \\
\text { AR } \\
\text { Pr }\end{array}$ & $\begin{array}{c}\text { III } \\
2 \\
1\end{array}$ & $\begin{array}{l}\text { I } \\
3 \\
2\end{array}$ \\
\hline D. & Alta Dominância e Alta Influência & $\begin{array}{l}\text { Falta Clareza de Metas de Gestão de Pessoas } \\
\text { Não ser aceito pelo chefe }\end{array}$ & Contemplação & Preparação & $\begin{array}{c}\text { Grupo } \\
\text { AR } \\
\text { Pr }\end{array}$ & $\begin{array}{c}\text { III } \\
1 \\
2\end{array}$ & $\begin{array}{l}\text { I } \\
3 \\
2\end{array}$ \\
\hline E. & Alta Dominância e Alta Conformidade & $\begin{array}{l}\text { Desempenho Insatisfatório } \\
\text { Censura devido à Ansiedade }\end{array}$ & Contemplação & Preparação & $\begin{array}{c}\text { Grupo } \\
\text { AR } \\
\text { Pr }\end{array}$ & $\begin{array}{c}\text { IV } \\
1 \\
1\end{array}$ & $\begin{array}{l}\text { II } \\
2 \\
2\end{array}$ \\
\hline F. & Alta Dominância e Alta Conformidade & $\begin{array}{c}\text { Falta de Feedback } \\
\text { Falta Reconhecimento }\end{array}$ & Contemplação & Ação & $\begin{array}{c}\text { Grupo } \\
\text { AR } \\
\text { Pr }\end{array}$ & $\begin{array}{l}\text { II } \\
2 \\
2\end{array}$ & $\begin{array}{l}\text { I } \\
3 \\
2\end{array}$ \\
\hline G. & Alta Conformidade & Falta Feedback & Contemplação & Ação & $\begin{array}{c}\text { Grupo } \\
\text { AR } \\
\text { Pr }\end{array}$ & $\begin{array}{l}\text { II } \\
2 \\
2\end{array}$ & $\begin{array}{l}\text { I } \\
3 \\
2\end{array}$ \\
\hline H.* & Alta Dominância e Alta Influência & Feedback Inconsistente & Contemplação & Ação & $\begin{array}{c}\text { Grupo } \\
\text { AR } \\
\text { Pr }\end{array}$ & $\begin{array}{c}\text { III } \\
1 \\
2\end{array}$ & $\begin{array}{l}\text { I } \\
3 \\
2\end{array}$ \\
\hline I .* & Alta Dominância e Alta Conformidade & $\begin{array}{l}\text { Falta Reconhecimento } \\
\text { Não ser aceito pelo chefe }\end{array}$ & Pré Contemplação & Contemplação & $\begin{array}{c}\text { Grupo } \\
\text { AR } \\
\text { Pr }\end{array}$ & $\begin{array}{c}\text { IV } \\
1 \\
1\end{array}$ & $\begin{array}{c}\text { II } \\
2 \\
2\end{array}$ \\
\hline $\mathbf{J}$. & Alta Estabilidade & $\begin{array}{l}\text { Desempenho Insatisfatório } \\
\text { Falta Reconhecimento / Feedback } \\
\text { Não ser aceito pelo chefe }\end{array}$ & Contemplação & Contemplação & $\begin{array}{l}\text { Grupo } \\
\text { AR } \\
\text { Pr }\end{array}$ & $\begin{array}{c}\text { III I } \\
2 \\
1\end{array}$ & $\begin{array}{c}\text { III } \\
2 \\
1\end{array}$ \\
\hline
\end{tabular}

Em relação à EDAO-R, o percentual, de acordo entre os avaliadores independentes foi de $70 \%$, considerado por Stemler (2004) como adequado para estimativa de consensos. No início do programa, cinco participantes apresentavam adaptação ineficaz moderada (Gr III), três apresentavam adaptação ineficaz leve (Gr II) e dois, adaptação ineficaz severa (Gr IV). Em todos os casos, a eficácia do setor afetivo-relacional estava comprometida, sendo que seis apresentavam adaptação pouco adequada e quatro, pouquíssimo adequada. Quanto ao setor da produtividade, cinco apresentavam adaptação pouco adequada, e os demais, adequada. 
Ao final dos programas, sete participantes haviam apresentado evolução positiva na eficácia adaptativa, sendo avaliados como adaptação eficaz (Gr I); dois terminaram com adaptação ineficaz leve (Gr II), ainda que ambos tenham apresentado evolução de sua avaliação inicial, adaptação ineficaz severa (Gr IV). Um dos casos não apresentou evolução. Ao término, nove participantes tiveram a avaliação eficaz no setor produtividade e apenas um manteve-se com a avaliação inicial, pouco adequada. A eficácia adaptativa do setor afetivo-relacional foi restabelecida em sete participantes. Em dois casos, apesar de terem melhorado na qualidade da adaptação do setor $\mathrm{AR}$, não chegaram a uma adaptação eficaz e em um dos casos não houve evolução.

Quanto à EEM, a avaliação realizada no início do programa revelou que sete participantes encontravam-se no estágio contemplação, segundo a classificação sugerida por McConnaughy et al. (1989), a saber, um foi classificado no estágio preparação, um no estágio ação e um no estágio précontemplação. Ao final do programa seis participantes haviam atingido o estágio ação, dois estavam no estágio contemplação e dois no de preparação. A evolução nos estágios de mudança deu-se em oito participantes, sendo que para dois deles foram realizadas ampliações do programa coaching de executivos de 10 encontros para 20 encontros, para a obtenção desta evolução.

Para aprofundar a análise da relação da eficácia adaptativa e dos estágios de mudança, os dados foram agrupados discriminando-se as respostas adaptativas mais frequentes por ocasião do início e do final do processo. No primeiro bloco estavam aqueles que pertenciam ao Gr II (adaptação ineficaz leve) no início do processo e haviam evoluído para Gr I (adaptação eficaz) ao final, composto por três participantes. Nas respostas consideradas ineficazes no setor afetivo-relacional, a dificuldade de relacionamento interpessoal com o superior imediato foi observada nos três, assim como a dificuldade em manter o autocontrole em situações de dificuldade em assumir riscos. Ao término dos programas observou-se a melhora na qualidade da eficácia adaptativa de todos os participantes deste grupo. Todos evoluíram da adaptação ineficaz leve para a adaptação eficaz. Como decorrência, todos relataram melhoria de autoestima e autoconfiança. Quanto ao estágio de mudança, os três iniciaram no estágio de contemplação e terminaram o programa no de ação, caracterizado por novas respostas e comportamentos em relação à situação que os levara a serem indicados para o programa de coaching .

Em um segundo bloco, dos quatro participantes que iniciaram com adaptação ineficaz moderada $(\mathrm{Gr}$ III) e apresentavam adaptação eficaz (Gr I) ao final do programa, dois estavam no início do processo, no estágio contemplação, um no estágio preparação e um no estágio ação. As respostas consideradas ineficazes, independentemente do estágio de mudança inicial, são similares. Todos apresentavam dificuldade de relacionamento com o superior, os pares ou a equipe. Das respostas consideradas ineficazes no setor afetivo relacional, as de dois participantes apresentaram classificação pouquíssimo adequada, devido, sobretudo à dificuldade em ser atencioso e valorizar a fala de um interlocutor, caracterizada como "dificuldade em ouvir". Dois referiram ansiedade para obtenção de resultados, da mesma forma que o "saber ouvir". Metade dos participantes relatou que a dificuldade é específica em relação à sua equipe, e a outra metade, que é específica em relação ao seu superior. A falta de delegação de tarefas era uma das respostas pouquíssimo adequadas no setor produtividade. Nos outros casos referem-se à falta de confiança na equipe, classificada então como setor afetivorelacional. Após a realização do programa observouse a melhora na qualidade da adaptação no setor afetivo-relacional nos quatro participantes. As respostas eficazes mais frequentes neste grupo são aquelas relativas ao exercício da liderança, como desenvolvimento da delegação, aceitar melhor e respeitar o ritmo de cada um dos membros da equipe, e para isto, a consequente flexibilização e melhoria de relacionamento em geral. Foi também vista como decorrente do programa a melhoria da autoestima e autoconfiança

Em um terceiro bloco, dois participantes que apresentavam adaptação ineficaz severa (GrIV) e evoluíram para adaptação ineficaz leve (Gr II), um estava no estágio contemplação e outro no estágio pré-contemplação, no início do processo. Os dois apresentam excesso de ansiedade e autocontrole deficitário, chegando à impulsividade em situações de pressão, dificuldade em ouvir a opinião dos outros, falta de delegação e dificuldade de comunicação. Estas respostas do setor afetivorelacional receberam a classificação "pouquíssimo adequada". No setor produtividade, ambos tiveram respostas classificadas como pouco adequadas. A realização do programa trouxe a evolução positiva de um deles do estágio contemplação para o estágio preparação e do outro, do estágio pré-contemplação 
para contemplação, mas nenhum deles chegou ao estágio de ação. Trouxe ainda a evolução positiva da adaptação ineficaz severa (GrIV) para a adaptação ineficaz leve (GrII). As respostas eficazes mais frequentes neste grupo são similares às dos grupos citados anteriormente, com o diferencial que os participantes precisaram trabalhar de forma mais intensa o setor afetivo-relacional.

O último participante foi avaliado inicialmente como tendo adaptação ineficaz moderada (Gr III) e no estágio de contemplação. As respostas ineficazes apresentadas são relativas ao setor afetivo-relacional, a saber: dificuldade de relacionar-se com seu superior, excesso de ansiedade em busca de resultados e dificuldade de comunicar-se, de expressar idéias em reuniões e em apresentações formais. Estas dificuldades tiveram, todavia, impacto no setor produtividade. Este participante antes do início do programa já se encontrava com forte conflito com seu superior. Apesar de ter sido indicado para o programa, a empresa optou por demiti-lo. Efetivamente, ele não apresentou evolução em sua eficácia adaptativa.

De acordo com o PPA, sete participantes apresentaram, no início do programa, perfil inadequado de liderança. Não apresentavam alta influência seguida da alta dominância (Duarte, 2006). Apenas um participante apresentou alta influência secundada por alta dominância. Os dois outros também apresentaram um bom perfil para a liderança, mas com o predomínio em alta dominância. Quanto à eficácia adaptativa, estes três participantes apresentaram evolução positiva em seus recursos adaptativos, saindo do Gr III para o $\mathrm{Gr}$ I.

Pelo questionário AAD foi possível obter tanto a percepção do participante em relação ao ambiente como quanto de feedback e de reconhecimento recebeu de seu superior imediato. Permitiu também avaliar quanto de esforço teria realizado em busca de seus objetivos e a clareza que possuía de possíveis déficits de desempenho. Seis participantes relataram a falta de feedback de seus superiores como o motivo principal de não estarem ajustados às suas expectativas. Quanto ao estágio de mudança, todos estavam no de contemplação. Desempenho percebido como insatisfatório foi mencionado por quatro participantes, os quais apontaram as condições de gerenciamento a que estão submetidos como a causa de seus problemas.

A análise dos dados foi concluída com uma avaliação qualitativa, em que se buscou o cruzamento dos dados obtidos na EDAO-R e da
Escala de Estágios de Mudança para cada um dos perfis predominantes da Personal Profile Analysis PPA; e a análise dos resultados do instrumento de autorrelato AAD ajudou a completar as análises. Cinco participantes tinham como fator predominante, de acordo com o PPA, a dominância. Todos evoluíram positivamente após o programa de coaching de executivos, tanto na qualidade de sua eficácia adaptativa como em seus estágios de mudança. No tocante à autopercepção de seu desempenho (AAD), todos mencionaram problemas advindos do ambiente - ora do chefe, ora da equipe. Apenas um apresentou a influência como característica predominante em seu perfil. Evoluiu da adaptação ineficaz moderada para a adaptação eficaz, mantendo-se no estágio ação. Os dois participantes com perfil preponderante de estabilidade admitiram ter desempenho insatisfatório e também queixaram-se de falta de feedback por parte dos superiores (AAD). Em um dos casos houve evolução positiva tanto na qualidade da eficácia adaptativa como no estágio de mudança. No outro caso a evolução não pôde ser verificada no mesmo ambiente organizacional por causa da demissão do participante. Os dois com perfil preponderante de conformidade relataram na AAD que precisariam de feedback de seu desempenho e também de reconhecimento. Ambos tiveram evolução positiva de sua eficácia adaptativa após o programa de coaching de executivos e evoluíram do estágio contemplação para o de ação.

\section{DISCUSSÃO}

Pode-se observar que parte das dificuldades enfrentadas pelos participantes que teriam dado origem à indicação de um programa de coaching de executivos para eles deveu-se, de um lado, à falta de compreensão dos superiores quanto às percepções e expectativas que o participante tinha de seu ambiente (superiores e colegas), e do outro, à falta de percepção dele próprio sobre a necessidade de ampliar ou modificar suas atitudes, de forma a adequá-las às exigências deste ambiente. Considerou-se relevante para o programa de coaching de executivos a realização do PPA. Por meio desta ferramenta pôde-se levantar o perfil predominante do participante e seus possíveis ajustes e desajustes à sua função.

A informação sobre o estágio de mudança medida no início do programa por meio da EEM também contribuiu para a elaboração de estratégias no decorrer do tempo. Percebeu-se que o estágio de 
mudança inicial tem relação com a rapidez e a eficácia com que o programa se desenvolveu. A EEM, ao ser utilizada como parte do processo de coaching de executivos, apresentou-se de utilidade, considerando-se que orientou a escolha mais adequada dos procedimentos adotados, assim como a modalidade de intervenção que sensibilizou para a mudança (Milaré \& Yoshida 2007). Conforme o esperado, não se observou relação entre os diferentes estágios de mudança e a qualidade da eficácia adaptativa. Por serem construtos independentes, sugere-se que a avaliação de candidatos a programas de coaching de executivos inclua as duas medidas: estágio de mudança e de eficácia adaptativa (Yoshida \& Enéas, 2004).

Todos os participantes indicaram, no início do programa, sua disponibilidade para mudar seu comportamento em sua Autoanálise de Desempenho (AAD). Apontaram a falta de feedback e a falta de reconhecimento por parte de seus superiores como causas dos déficits de desempenho, o que é compatível com o ponto de vista de Kampa-Kokesch e Anderson (2001), segundo o qual, o componente comum e relevante nas diferentes metodologias de coaching é a necessidade do feedback, que, quando fornecido com dados confiáveis, leva os executivos a se engajarem com confiança no processo.

As estratégias cognitivas utilizadas para estes ganhos comportamentais foram absorvidas pelos executivos, que puderam rapidamente ver o foco de trabalho por meio de uma diferente percepção e o benefício potencial decorrente. Para evitar o retorno ao comportamento anterior (Peltier, 2001), cada participante foi orientado a traçar um plano de ação pós-coaching, identificando todos aqueles que consideraram importantes para a manutenção dos comportamentos, envolvendo as pessoas de sua relação que poderiam ajudar no estabelecimento consolidado dos novos comportamentos.

Os resultados desta pesquisa corroboraram com a expectativa teórica, pois a EDAO-R permitiu a identificação de qual setor da personalidade estava mais comprometido e quais os tipos de respostas apresentavam-se como mais frequentes em processos de coaching de executivos. Permitiu também uma avaliação do grau de comprometimento da eficácia adaptativa, por meio da identificação das respostas pouco ou pouquíssimo adequadas. Percebeu-se que quanto maior o comprometimento da eficácia adaptativa, mais recursos precisarão ser disponibilizados ao executivo para que ele se desenvolva, e, decorrente disto, uma postura mais ativa por parte do coach.
Como parte do programa de coaching os executivos receberam feedback do coach, assim como de seus superiores, e como decorrência, observaram aumento de sua autoconfiança, corroborando a teoria (O'Neill, 2001; Kilburg, 2000). Assim sendo, as respostas eficazes relatadas tanto pelos executivos quanto por seus superiores são principalmente aquelas relativas ao restabelecimento de relações interpessoais, melhor aceitação e respeito ao ritmo e forma de trabalho de cada um dos membros da equipe, o desenvolvimento da delegação de tarefas e consequente flexibilização, além da melhoria da comunicação em geral. $\mathrm{O}$ autocontrole diante de situações adversas também foi desenvolvido.

A EDAO-R, quando incorporada ao programa, permitiu identificar quais situações que estariam gerando desprazer e conflito, medindo sua evolução tanto por meio das próprias respostas do executivo quanto pelo depoimento das pessoas que convivem com ele. As avaliações da EDAO-R em conjunto com o PPA mostraram-se úteis na escolha das estratégias e ferramentas utilizadas pelo coach durante os módulos do programa. Por outro lado, a EEM permitiu identificar o grau de prontidão do executivo para enfrentar novas solicitações do ambiente. Estas informações, adicionadas aos feedbacks que ele já possuía (ou não) e que foram evidenciados pelos resultados da AAD, colaboraram para o sucesso do programa.

\section{CONSIDERAÇÕES FINAIS}

Apesar de este estudo ter sugerido que programas de coaching de executivos podem ser eficientes e que certa sistematização dos procedimentos é desejável, é preciso observar que eles não devem se tornar procedimentos rigidamente padronizados. A forma como as técnicas são introduzidas e os momentos são totalmente particulares a cada caso. Para estas discriminações faz-se necessário que o coach tenha um bom nível de preparo para o exercício desta atividade, requerendo forte base e formação humanista, vivência organizacional diversificada, ser um profissional sênior e seu histórico profissional garantir credibilidade e confiança, sendo preferencialmente um psicólogo (Milaré, 2004).

Os resultados desta pesquisa permitem concluir que, da mesma forma que na psicoterapia, não se espera que o processo de mudança no coaching de executivos se dê de forma repentina, mas é função de todo um contexto que precisa ser avaliado (Yoshida 
\& Enéas, 2004). Ademais, perfis comportamentais com o predomínio do estilo "dominância" podem ser mais predispostos a enfrentar problemas, principalmente quando combinados com condições de gerenciamento a que o executivo está submetido em seu ambiente de trabalho. Nesta medida, uma avaliação que considere o perfil de personalidade do executivo, sua eficácia adaptativa, o estágio de mudança em que ele se encontra, integrada às características do ambiente organizacional, parece ser útil na abordagem preventiva dos problemas psicológicos, facilitando a opção pelo programa ou intervenção mais adequado. Acredita-se também que este estudo tenha trazido a possibilidade de ampliar a utilização de instrumentos psicológicos como a EDAO-R e a EEM, que tradicionalmente são empregados no campo clínico, estendendo-os às organizações, o que sugere sua utilidade de aplicação a diferentes contextos. Ele também permitiu demonstrar que os fundamentos da psicologia podem ajudar a aperfeiçoar o trabalho, desde que privilegiados a ética e os princípios da dignidade humana.

Poucos estudos sistematizados são encontrados na literatura científica a respeito de programas de coaching de executivos. Os resultados deste estudo contribuem parcialmente para o preenchimento desta lacuna. Este estudo contém limites, como o fato de os processos de coaching terem sido realizados pela primeira autora. Em pesquisas futuras sugere-se o estudo de processos de coaching conduzidos por outros profissionais. Ademais, amostras diversas e maiores deverão garantir maior capacidade de generalização dos resultados. Finalmente, sugere-se que novas pesquisas incluam o seguimento dos resultados por ao menos seis meses ou um ano.

\section{REFERÊNCIAS}

Darraugh, B. (2000). Coaching and Feedback. American Society for Training \& Development: Info-line, Issue 9006, $7-12$.

DiClemente, C.C., \& Prochaska, J.O. (1982). Self-change and Therapy Change of Smoking Behavior. Addictive Behavior, 7, $133-142$.

Duarte, M. (2006). Desenvolvimento de Potencial através do DISC. Monografia do curso de Especialização em Desenvolvimento do Potencial. Orientação de Sueli A. Milaré. Campinas: PUC Campinas.

Ducharme, M. (2004). The Cognitive-Behavioral Approach to Executive Coaching. Psychology Journal: Practice and Research, 56(4), 214-224.
Harris, M. (1999). Look, it's an I - psychologist - no, it's a trainer -no, it's an executive coach. TIP, 36(3), 1-5.

Judge, W.Q., \& Cowell, J. (1997). The brave new world of executive coaching . Business Horizons, 40 (4), 71-77.

Kampa-Kokesch, S., \& Anderson, M., (2001). Executive Coaching : A Comprehensive Review of the Literature. Consulting Psychology Journal, 53, 205 - 228.

Kilburg, R. R. (2000). Executive coaching : Developing managerial wisdom in a world of chaos. A.P.A. Washington, DC.

Lipp, M.E.N. (2005). Stress e o Turbilhão da Raiva. São Paulo: Casa do Psicólogo.

McConnaughy, E.A., Prochaska, J.O., \& Velicer, W.F.(1983). Stages of Change in psychotherapy: Measurement and profiles. Psichotherapy, 26, $368-375$.

Marston, W. M., (1928). Emotions of Normal People. New York.

Milare, S.A. (2003). Manual do Programa de Coaching . Korum Consultoria. Manuscrito. S.P.

Milaré, S.A. (2004). Investimento com Retorno Garantido. Revista T\&D-Inteligência Corporativa, 12 (132), 20 - 22.

Milaré, S.A., \& Yoshida, E.M.P. (2007). Coaching de executivos: adaptação e estágio de mudanças. Psicologia: Teoria e Prática. 9 (1), 83 - 105.

O’Neill, M. (2001) Coaching : Treinando Executivos (Lasserre,Trad). São Paulo: Futura.

Oxford Dictionary (2005). Oxford University Press. New York.

Peltier, B. (2001). The psychology of executive coaching . Florence, KY: B. Routledge.

Simon, R. (1989). Psicologia Clínica Preventiva: novos fundamentos. São Paulo: EPU (original publicado em 1983, pela Vetor).

Simon, R. (1995). Teoria da Evolução humana. Mudanças, 3, 25-36.

Simon, R. (1997). Proposta de Redefinição da EDAO. Boletim de Psicologia. XI. VII (107), 85-94.

Stemler, S. E. (2004). A comparison of consensus, consistency, and measurement approaches. Practical Assessment, Research \& Evaluation, 9(4). Disponível em http://www.pareonline.net/getvn.asp?v=9\&n=4. Acesso em 18.12.2007.

Stern, L.R. (2004). Executive Coaching : A Working Definition. Consulting Psychology Journal: Practice and Research, 56(3):154 - 162.

TTI - Target Training International (2000). Identificando $e$ Gerenciando Talentos. São Paulo: Venko Consulting.

Thomas International (1996). Technical Manual. São Paulo: Thomas.

Whitmore, J. (2006) Coaching para Performance. Rio de Janeiro: Qualitymark.

Yoshida, E.M.P. (1999). EDAO-R: Precisão e Validade. Mudanças: Psicoterapia e Estudos Psicossociais, 7 (11), $189-213$. 
Yoshida, E.M.P., Primi, R.. \& Pace, R.. (2003). Validade da Escala de Estágios de Mudança. Estudos de Psicologia, 20 (3), $7-21$.

Yoshida, E.M.P., \& Enéas, M.L. (2004) Psicoterapias

Recebido em 19/03/2008 Psicodinâmicas Breves: propostas atuais. SP: Alínea.

Aceito em 14/08/2008

Endereço para correspondência : Sueli A. Milare, Av, John Boyd Dunlop, s/n, Jd Ipaussurama, CEP 13060-904, Campinas-SP, Brasil. E-mail: sueli.milare@ puc-campinas.edu.br 
